\title{
From Faculty to Change Agent: Lessons Learned in the Development and Implementation of a Change Workshop
}

\section{Dr. Ella Lee Ingram, Rose-Hulman Institute of Technology}

Ella L. Ingram is an Associate Professor of Applied Biology and Biomedical Engineering and Director of the Center for the Practice and Scholarship of Education at Rose-Hulman Institute of Technology. Her educational research interests include promoting successful change practice of STEM faculty, effective evolution and ecology instruction, and facilitating undergraduate research experiences. Her teaching portfolio includes courses on: nutrition, introductory biology, ecology and environmental studies, evolution, evolutionary medicine, and research practices in science.

\section{Dr. Richard A House, Rose-Hulman Institute of Technology}

Richard House is Professor of English at Rose-Hulman Institute of Technology. He received a B.A. from Illinois Wesleyan University and M.A. and Ph.D. from the University of California, Irvine. In addition to engineering communication and pedagogy, he has scholarly interests in sustainability and Shakespeare.

\section{Dr. Steve Chenoweth, Rose-Hulman Institute of Technology}

Steve Chenoweth is Associate Professor of Computer Science and Software Engineering at Rose-Hulman Institute of Technology. Previously he had a career in software development, at NCR Corp. and at Bell Labs. He specialized in starting new projects, and in reviewing such projects. All of these software development projects involved some associated social change. At Rose-Hulman he has been involved in starting the bachelor's and master's programs in software engineering.

\section{Dr. Kay C Dee, Rose-Hulman Institute of Technology}

Kay C Dee received a B.S. degree in chemical engineering from Carnegie Mellon University, and M.Eng. and $\mathrm{Ph}$.D. degrees in biomedical engineering from Rensselaer Polytechnic Institute. After completing her graduate work, Kay C joined the Department of Biomedical Engineering at Tulane University in New Orleans, Louisiana, and later joined the faculty at Rose-Hulman Institute of Technology. She served as the founding Director of the Rose-Hulman Center for the Practice and Scholarship of Education, and is currently the Associate Dean of Learning \& Technology as well as a founding member of the team that annually delivers Rose-Hulman's 'Making Academic Change Happen' workshop.

Kay $\mathrm{C}$ has received a number of awards for teaching, research, and mentoring, including the Louisiana "Professor of the Year" award from the Carnegie Foundation for the Advancement of Teaching, a CAREER award from the National Science Foundation, the Tulane University "Inspirational Undergraduate Professor" award; the Tulane University President's Award for Excellence in Undergraduate Teaching; the Graduate Alliance for Education in Louisiana Award for Excellence in Mentoring Minority Researchers; the honor to serve as a Teaching Fellow for the National Effective Teaching Institute; and more.

Dr. Jameel Ahmed, Rose-Hulman Institute of Technology

Jameel Ahmed is Associate Professor and Head of the Department of Applied Biology and Biomedical Engineering at Rose-Hulman Institute of Technology. He has been teaching at Rose-Hulman since 1999, and his technical interests lie in the areas of quantitative physiology and neuroprosthetics. He also has interest in helping develop leadership skills in others, as is evidenced by his involvement in Rose-Hulman's Leadership Advancement Program, and the Making Academic Change Happen (MACH) workshop

\section{Dr. Julia M. Williams, Rose-Hulman Institute of Technology}

Dr. Julia M. Williams is Executive Director of the Office of Institutional Research, Planning, and Assessment \& Professor of English at Rose-Hulman Institute of Technology. Her research areas include technical communication, assessment, accreditation, and the impact of pen-based technologies on learning and teaching. Her articles have appeared in the Journal of Engineering Education, International Journal of Engineering Education, IEEE Transaction on Professional Communication, and Technical Communication Quarterly, among others. 


\section{Dr. Craig G Downing, Rose-Hulman Institute of Technology}

Craig G. Downing is Department Head and Associate Professor of Engineering Management at RoseHulman Institute of Technology. His teaching responsibilities are focused on delivering graduate-level instruction related to Operations and Quality Systems. His interests are rooted in Academic-Industrial partnerships, Process Improvement, and Action Research in Engineering Management. He is a certified Lean Six Sigma Master Black Belt.

Dr. Donald E. Richards, Rose-Hulman Institute of Technology 


\title{
From Faculty to Change Agent: Lessons Learned in the Development and Implementation of a Change Workshop
}

\begin{abstract}
Agents of change face opposition from multiple angles, yet see opportunity in unexplored corners. In higher education, pressures are mounting: the global economy is uncertain and dynamic, intellectual content is widely accessible, institutional costs are rising, and alternatives to a traditional degree are growing. In this paper, we describe the evolution of the Making Academic Change Happen (MACH) workshop, in which both faculty and staff learn to become effective change agents. The fundamental learning outcome from our workshop planning and development process was the realization that becoming a change agent requires the acquisition of skills outside the realm of typical faculty experience-strategic thinking, creating working partnerships, and garnering support for far reaching ideas. To be successful, faculty must intentionally learn these skills and practice them in advance of their deployment. As a result, MACH is a manifestation of the philosophy "you have to do it to know it" (i.e., practice and feedback help develop mastery). While we believe that the in-person MACH experience is invaluable for supporting change initiatives, we have identified key resources that individuals can utilize on their own. These resources are readily available, inexpensive, and outside the realm of typical faculty development, making them essential in the process of becoming a change agent.
\end{abstract}

\section{Introduction}

Within the science, technology, engineering, and mathematics (STEM) education community, there are repeated calls for changing the way we educate our students (e.g., the National Academy of Engineering's Engineer of 2020; President Obama's Educate to Innovate program; AAU's Undergraduate STEM Education Initiative). From the broad perspective of external stakeholders, reform of STEM education may enable graduates to better meet employers' changing needs. More broadly, initiatives such as the NAE's Grand Challenges for Engineering hope to recruit undergraduate engineers into the effort to find engineering solutions to pressing social needs around the world. These broad, systemic social needs, of course, accompany the imperatives imposed by data about student learning and by questions about whether traditional instructional methods_-particularly in large lecture courses—best serve students.

If these forces motivate change, though, they are also embedded in institutional systems that make change difficult. Program accreditation is one especially potent force limiting the breadth and depth of proposed changes. In engineering fields, the Accreditation Board of Engineering and Technology, Inc. (ABET) specifies for U.S. and international programs minimally expected outcomes of a technological education. ABET introduced the revised outcomes for Engineering Criteria $2000^{1}$ to drive changes in engineering education practice-such as promoting more substantial education in communication and ethics - but many programs' and institutions' approaches to the ABET requirements have now become codified, and administrators now examine proposed changes to curriculum or pedagogy, asking whether they pose any risk to continuing accreditation. Programs that have been successfully placing graduates into desirable jobs may be similarly constrained by their own success. Such factors can reinforce an institutional resistance to change that is familiar to many faculty members. At its worst, new ideas can be re- 
jected, in a vicious circle of institutional inertia, by appeals to traditions at the core of the institution's identity.

Put simply, STEM educators are used to discussions of change, but those discussions are typically limited to the content of desirable changes, neglecting the skill set necessary to effect these changes in the complex organizational environments in which we work. For example, change has been targeted at the course and curriculum levels, focusing on teaching and learning methods and proving their efficacy ${ }^{2}$. While beneficial, these activities have not fostered the underlying strategies - motivation, communication, collaboration, and persuasion - that are the foundation for change on larger, more institutional levels. These change strategies are well documented in the literature of other disciplines, such as organizational psychology and behavior ${ }^{3,4}$, but have not been brought into the conversation within STEM education in a rigorous, accessible way. The Making Academic Change Happen (MACH) workshop was conceived as an answer to this problem. In this paper, we describe the workshop development process, outcomes from multiple implementations of the workshop, and key resources for change agents.

\section{Methods}

At Rose-Hulman Institute of Technology, we envisioned a workshop that could address the needs of faculty and administrators who wished to make systemic change in STEM education. We considered our own experience with change on our campus, as well as our reputation for being a leader in STEM education innovation ${ }^{2}$. We also decided to explore the fundamental dimensions of change as we saw it embodied in our own projects, successes and failures alike.

The eight members of the facilitator group come from five different departments; all have faculty status and are tenured. Two facilitators are department heads, while three have half-time administrative positions: the group's efforts are coordinated by two of these faculty members with half-time administrative appointments (one in institutional research, the other in the teaching and learning center). The facilitator group works with administrative approval but without a dedicated budget or ongoing, committed administrative financial support.

Each facilitator has led or been a driving force on a change project beyond the department level. For example, one facilitator was part of establishing Rose-Hulman's first freshman livinglearning community, the Home for Environmentally Responsible Engineering (HERE), focused on sustainability. Setting up this program required deep, ongoing collaboration among faculty colleagues in different departments, as well as professional staff in admissions, student affairs, and residential life; in two years, the program reached its capacity for student participation. As a leader on this project, the facilitator advocated for the program to administration, wrote grant applications, designed and revised curriculum across several interdisciplinary courses, and performed outreach to allied groups on campus and within the broader community. All of the facilitators have such direct experience creating change at Rose-Hulman.

Our initial work included a review of current literature on change, including work by Henderson, et al. on the subject of facilitating change in undergraduate STEM education ${ }^{5}$. Henderson's analysis developed a four-part typology of change strategies based on the intended outcomes (predetermined or emergent) and the focus of the change effort (the environment or individuals). After 
reviewing nearly 200 reports of STEM change, they found that the combination of emergent outcomes and institutional focus (a category they call "Developing: Shared Vision") was the least described. This observation revealed a key question for the MACH development team: perhaps the absence of emerging systemic change in STEM education reflects pervasive error in change agents' chosen focus and intended outcome. Borrego et al. agree in part with this conclusion - they found that diffusion of innovation required "plans that promote transitions to stages of adoption beyond awareness" (pg. 202) ${ }^{2}$ and a focus on stakeholders rather than on a specific activity to be implemented. In designing our workshop, we decided to help faculty and administrators develop shared visions for change, learn tools that can help them facilitate emergent change from their work as change agents, and create plans for action on their home campuses.

The MACH workshop develops strategies for emergent changes of institutional environments over three intensely focused, hands-on days. MACH is organized around three themes: "Knowing Yourself," "Cultivating an Allied Community of Colleagues," and "Making Change Happen on Campus." The "Knowing Yourself" segment helps participants focus on skills and change aspects that an individual faculty member can control, including interactions with students and colleagues. This segment considers personality assessment, communication, risk assessment and mitigation, and diversity. The "Community of Colleagues" segment focuses on building teams, garnering support, and maintaining effective relationships with others. The "Making Change Happen on Campus" segment targets developing measurable objectives and assessment for the project, building and implementing partnerships, identifying sources of support and resistance, and creating action plans for moving the project forward. Each day is organized into four sessions. Every session includes time for learning, practice, and feedback from facilitators and participants (Table 1). In addition to the day's activities, participants create community through evening activities that help individuals move along a path toward becoming journeyman change agents. 
Table 1. Example Day (Community of Colleagues) with Activities and Action Plan Development

\begin{tabular}{|c|c|c|c|c|}
\hline Time & Early Morning & Late Morning & Early Afternoon & Late Afternoon \\
\hline Session & Creating Teams & $\begin{array}{l}\text { Developing } \\
\text { Influence }\end{array}$ & Building Buy-In & $\begin{array}{c}\text { Difficult } \\
\text { Conversations }\end{array}$ \\
\hline Activity & $\begin{array}{l}\text { Identify critical ele- } \\
\text { ments of team for- } \\
\text { mation; self-identify } \\
\text { role in typical team }\end{array}$ & $\begin{array}{l}\text { Practice applying prem- } \\
\text { ises of influence to } \\
\text { scenario; identify key } \\
\text { elements in past expe- } \\
\text { rience }\end{array}$ & $\begin{array}{l}\text { Identify common re- } \\
\text { sponses to objections; } \\
\text { develop familiarity with } \\
\text { response scripts; prac- } \\
\text { tice variations }\end{array}$ & $\begin{array}{l}\text { Map features of exam- } \\
\text { ple conversation; identi- } \\
\text { fy critical elements in } \\
\text { given conversation; } \\
\text { practice successful lan- } \\
\text { guage }\end{array}$ \\
\hline Action Plan & $\begin{array}{l}\text { Identify six close col- } \\
\text { leagues with potential } \\
\text { for shared vision; iden- } \\
\text { tify pros/cons and ap- } \\
\text { proach for each }\end{array}$ & $\begin{array}{l}\text { Create possible influ- } \\
\text { ence strategies to use } \\
\text { when assembling team } \\
\text { or making request giv- } \\
\text { en target }\end{array}$ & $\begin{array}{l}\text { Generate three re- } \\
\text { sponses to most likely } \\
\text { objections from col- } \\
\text { leagues at institution }\end{array}$ & $\begin{array}{l}\text { Predict difficult conver- } \\
\text { sations at institution; } \\
\text { develop two approaches } \\
\text { (e.g., me, me, and; I feel) }\end{array}$ \\
\hline $\begin{array}{l}\text { Source } \\
\text { Material }\end{array}$ & $\begin{array}{l}\text { On Teams, Harvard } \\
\text { Business Review, } \\
2013\end{array}$ & $\begin{array}{l}\text { Influence, Cialdini, } \\
2006\end{array}$ & $\begin{array}{l}\text { Buy-In, Kotter \& } \\
\text { Whitehead, } 2010\end{array}$ & $\begin{array}{l}\text { Difficult Conversations, } \\
\text { Stone, Heen, \& Patton, } \\
1999\end{array}$ \\
\hline $\begin{array}{l}\text { Additional } \\
\text { References }\end{array}$ & $\begin{array}{l}\text { Janz et al. } 1997 \\
\text { Cohen \& Bailey } 1997 \\
\text { Mathieu et al. } 2008\end{array}$ & $\begin{array}{l}\text { Cialdini \& Goldstein } \\
2004\end{array}$ & & $\begin{array}{l}\text { Jacobs et al. } 2011 \\
\text { Meyer } 2006 \\
\text { Weeks } 2001\end{array}$ \\
\hline
\end{tabular}

The outcomes we present in this paper have emerged from our work with six groups of participants on MACH content (in two full-length workshops and four multi-part, targeted sessions). These participants represent a wide range of institutions and roles within their institutions. For example, participants' home institutions include University of Illinois (R1 flagship campus), Utah State University (R1 regional), Michigan Tech University (technical university), Universiti Teknologi Malaysia (R1 international), and Canterbury School (college preparatory K-12). This broad range of institution type resulted in comparative questions about institutional culture (more below). The academic roles of participants ranged from those of the early career ( Ph.D. students in traditional STEM disciplines, engineering education Ph.D. students, and untenured assistant professors) to the roles of mid-career or well-established faculty or administrators (department heads, student affairs directors, first year program coordinators, and deans). The proposed projects were similarly varied, representing course-level, program-level, and campus-level change about evenly. As a result of the diversity of participants in the MACH workshop and their associated projects, we think the lessons we present here are broadly applicable.

We employed multiple feedback mechanisms to better target the working sessions and to direct the learning of the participants. An external team from Virginia Tech's Department of Engineering Education developed and implemented an assessment plan for outcomes related to the workshop participants and to provide real-time feedback about our behavior, facilitation approach, and efficacy. Two daily briefings allowed the team to speak with a common voice, manage the 
developing collaborations, and steer certain activities in profitable directions. Formal assessment data about participant development is forthcoming for the external evaluators and is not reported here.

\section{Results}

Outcome 1: Becoming a change agent requires acquisition of new skills and practicing these skills before using them in a high-stakes situation.

In the MACH workshops, participants practice novice skills in various areas. For example, participants practiced and observed examples of "difficult conversations" from the book Difficult Conversations: How to Discuss What Matters Most ${ }^{6}$. The drama of this role-playing has allowed our participants to anticipate similar encounters likely to arise as they pursue their change initiatives, and to engage in revealing discussions regarding how those encounters could go. This conference activity epitomized the value of practicing skills for change prior to undertaking the real thing. Because of the stakes and the emotions involved in a face-to-face interaction what is said can be vastly different from what is perceived as having been said, the ability to swim in such waters, with merely simulated sharks, was felt by our participants to be profitable.

As a second example, MACH participants reflected on ways they might overcome "standard objections to change" that emerge reflexively to thwart a threatened change. For example, the retort "That will never work here" can be heard about any new academic idea. Our participants were presented with these well-known objections, taken from Buy-In: Saving Your Good Ideas from Getting Shot Down ${ }^{7}$. In the context of their own ideas for academic change, they reflected on how to respond to these statements. Strategies included overcoming natural inclinations, like excluding opponents from discussions or fighting attacks with exhaustive data.

We believe the skills developed fostered by MACH cannot be acquired easily in something less than an immersive setting with guidance to shape nascent skills. A high level of participation and targeted, critical, wide-ranging feedback are required.

\section{Outcome 2: Change agents must understand their institutional contexts.}

Workshop organizers found special value in the fact that participants came from different kinds and sizes of institutions. Even within a category, schools vary in idiosyncratic ways which don't become obvious until they are compared with one another. The contrast enabled our participants to see, from someone else's eyes, the predicaments that they were facing, enabling them to frame in a more objective way their interest in changing their own institutions. In our final-day session on building partnerships, participants identified success criteria and developed action plans for implementing change and for recruiting on-campus partners-a natural bridge from partnering during the many sessions at MACH.

Our participants partnered with people from other schools, so as to gain this value. Then they drew images of the "engines and anchors" for change at their own school ${ }^{8}$, reflecting institutional factors that can be harnessed to propel a change initiative ("engines” for change), as well as those that must be overcome ("anchors" holding the status quo in place). By creating their own content, the participants felt the individual responsibility they truly own, in making change happen. They were encouraged to probe each anchor down to root causes, using the "Five Whys" 
technique (originally developed for the Toyota Production system ${ }^{9}$, now well-known and used in quality control systems such as Six Sigma ${ }^{10}$, Kaizen ${ }^{11}$, and lean manufacturing.). And, based on their weighing easy and hard spots in their paths, this assessment allowed participants to form plans for next steps and to spot necessary or advantageous partnerships. While faculty commonly partner in research papers with colleagues who share their interests, partnering to produce change typically requires a more intense search to find common interests. Making academic change happen is not synonymous with following through on an initiative which already enjoys executive sponsorship. Most ideas bubble up from the bottom, and for a long time they occupy no position of inherent strength in the academic organization: a coalition needs to coalesce. With this foundation, participants identify the unique opportunities and constraints of their individual academic environments and share strategies for expanding and implementing visions of academic change.

\section{Outcome 3: Change agents require specific structures of support.}

Through our work, we discovered that two structures of support were particularly meaningful: a community of change and uninterrupted time. MACH facilitators do not use a traditional lecture structure, instructing participants on the "best" way to approach a task. Instead, we share information with participants and promote discussion within teams and across the entire group, asking participants to collaborate as they work on skills development in the context of their individual change projects. The community is therefore powerful; enriched by diverse experiences, creative ideas, and honest discourse. Further, it is empowering, helping participants to pursue their projects. After the workshop concludes, facilitators continue to work with participants to track their progress, offer advice from an outside perspective, and provide support. Having experienced such mentoring, we have learned that participants must not only partner with agents who support and can facilitate their specific projects, but also seek such feedback from other change agents across their campuses and in their professional communities.

In addition to interaction with the community of change around them, it was also important to allow quiet, reflective time for participants to engage with their projects. As the workshop progressed, we spent less time working in groups and more time working on individual change projects, with the last day being almost completely devoted to project planning. One advantage of attending a workshop away from the participants' campuses was to allow them to get away from normal work obligations and focus exclusively on their change project. By providing uninterrupted time, and by using appropriate prompts, participants were able to develop detailed, indepth implementation plans for their change projects. For instance, one project aimed to create teaching opportunities for graduate students at a medical school. The participants engaged in this process were able to do some specific planning as to which members of faculty and administration they should contact to help them promote, fund, and deliver this program and how to frame their project in ways that would allow them to convince these partners of the program's value. The emphasis on setting aside time to do what's important (as opposed to what is urgent) is common in the leadership and management literature; for instance, it is encoded in Stephen Covey’s “Quality \& Personal Leadership” quadrant in the Seven Habits of Highly Effective People ${ }^{12}$. MACH participants are taught to maintain a project calendar with non- negotiable milestone dates and to schedule uninterrupted time blocks with a change partner, away from the office, to work on the project. Several participants mentioned after the workshop that they found this focused, on-task time invaluable for advancing their change action. 


\section{Discussion}

Throughout their careers, faculty can benefit from a key lesson from the education research advocated by ASEE: effective learning requires engagement with the content, ideally in collaboration with peers ${ }^{13,14,15}$. The MACH workshop uses various forms of engagement during the sessions. Role-playing sessions in particular create "productive failure" 16 , allowing participants to experience the inadequacy of their knowledge or skills, to work to resolve that inadequacy, and then to try again to reach competency ${ }^{17}$. In Dreyfus's formulation of adult skills development, competency is the stage at which the individual chooses among the vast number of applicable rules or procedures without absolute certainty of what action is suitable, but with full responsibility for the decision. MACH participants practice skills multiple times in multiple scenarios, maximizing the likelihood of appropriate responses to future events. Further, we use the experiences of the participants themselves to generate additional understanding, consistent with lessons of How People Learn ${ }^{18}$. Having practiced and prepared scripts reduces the participants' anxiety about advocating for change and may increase their ability to foster acceptance of the change by the community.

The critical role of understanding institutional context is not a novel discovery. Eckel's On Change III $^{19}$ devotes a chapter to analyzing institutional culture, a major activity within the MACH experience. The guiding questions formulated by Eckel encourage an anthropological approach to considering culture. MACH participants become Eckel's "sympathetic outsiders" for one another during the workshop, identifying key aspects of the culture to insiders. Tierney describes the importance of using an anthropological perspective, listing six key areas that define culture in higher education (environment, mission, socialization, information, strategy, and leadership) and provides several questions for each area to answer to develop a sense of culture ${ }^{20}$. Tierney noted that two institutions can have widely varying cultures, yet both can be effective. Essentially, effective change can look very different at two superficially similar organizations. Kezar and Eckel likewise recommend the cultural approach to advancing change (defined as working to understand, exploit, and embrace the organization's values and beliefs $)^{21}$. The MACH workshop provides developing change agents with these targeted questions, explorations, and challenges regarding institutional culture and their own relationships to that culture.

Institutional culture was particularly daunting for participants from research-intensive universities. These change agents were proposing not broad change in research-related matters, but transformative activity regarding STEM education practice. We found these individuals to be most interested in, and constrained by the cultures of departments or schools within the university. Once the perspective was focused in this way, change agents readily identified possible partners. Further, the group examined how, given very tight state funding and the uncertainty of grant funding, change projects could be accomplished without new money (utilizing existing resources or innovative mechanisms for funding. These discussions propelled forward the change agents from research-intensive institutions, despite initial feelings of significant challenge.

Much of what we have learned has come as a result of observing facilitators working with workshop attendees on their individual change projects. The relationship between facilitator and attendee models the ongoing support required for change to take root, no matter what the envi- 
ronment. During each session, as one or two facilitators introduce new content and the hands-on exercises in which participants apply it, the remaining facilitators circulate among the participants, listening to their ideas, offering support, and providing guidance as they make their plans to implement change on their own campuses. The importance of the facilitators' role was cited frequently in the observations made by the assessment team, as well as in the surveys completed by participants at the conclusion of the workshop. We see facilitators as peer coaches ${ }^{22}$-more experienced than attendees in planning and executing change projects, but not acting in the role of experts. Instead, they offer their own experiences with change, both successes and failures. The lack of hierarchy allows attendees to approach every facilitator as a peer, a status that faculty are more likely to find empowering as they enter into a new and challenging field of endeavor. Support and encouragement continue after the workshop is over. The emphasis during the workshop is to devise a change strategy that can be implemented back at the attendee's home campus. As is often the case, however, the change strategy may need to be revised as new circumstances arise; the change agent may also need ongoing feedback and support to ensure success. For this reason, MACH creates a community of peers - whether facilitators or attendees - who can support each other as they take on this work.

\section{Key Resources}

We recommend the acquisition of four different types of resources. First, change agents will benefit from targeted reading - in particular Kotter and Whitehead's Buy-In, Stone, Patton, and Heen's Difficult Conversations, and Harvard Business Reviews's On Teams ${ }^{23}$. The perspectives offered in these works were considered invaluable to MACH participants. Each book provides scenarios that any change agent can envision themselves experiencing; the strategies for solving them require careful study. Background reading that MACH facilitators found helpful is recommended as additional reading for participants: A.J. Kezar's "Understanding and Facilitating Organizational Change in the 21st Century”24, Eckel and Hartley’s “Developing Academic Strategic Alliances: Reconciling Multiple Institutional Cultures, Policies, and Practices”25, and Eckel et al.’s “On Change III Taking Charge of Change: A Primer for Colleges and Universities”19.

Second, change agents should work to develop a group of partners, including change leaders, who will help coordinate the process; contributors, who will participate in change through defined and specific roles; resource providers, who will supply information or resources; constituents, who may not participate but must be kept up-to-date regarding the process and vision; and constructive skeptics, who will provide thoughtful and useful critiques. With the assistance of these allies, the change agent can manage resistors, those individuals who are invested in preserving the status quo ${ }^{19}$. Change agents should consider the cultural context of their particular project and select team members who are likely to have credibility with the groups listed above. We additionally recommend that the change agent cultivate and maintain relationships with people who are agents of other types of change (including MACH participants and facilitators). These individuals are unlikely to directly contribute to the change project in question, but will contribute to the support, critical thinking, and fellowship needed by the change agent.

Third, change agents must make time for focused work. We recommend the obvious-a closed office door and noise canceling headphones - as a start. Better yet is a two hour appointment with another change agent at the local coffee shop to work individually on projects. Successful 
change agents schedule the time for on-task work, embrace change projects as part of their professional development, and make change projects public. Change agents use time to cultivate supporters and create accountability mechanisms.

Finally, change agents need an action plan (ideally contained within a large three-ring binder with multiple tabs). Critical elements of this plan include: an academic calendar noting vacations, finals, institution-level meetings (where a project might be announced or approved), personal constraints (conference trips, proposal due dates, etc.); a page to record four or five arguments against the change project and blank space in which to formulate multiple responses (consistent with Buy-In); multiple blank pages to record next steps; a team-tracking page, on which members and their respective roles and contributions are described and updated; a partnership section, to hold letters of commitment or support or other notes about the relationship; and a summary of "engines and anchors" to annotate or modify as the project progresses. Finally, the action plan should include milestone dates-as critical to the advancement of the project as a publication or abstract submission deadline is to professional advancement. By collecting these materials and actively using the action plan through focused work, the change agent facilitates the birth and development of the change project.

In total, these resources are readily available and inexpensive-but are seldom acquired or cultivated in typical faculty development, making them essential in the process of becoming a change agent. We recommend that all individuals embarking on a change project marshal these resources and prioritize their consistent use.

\section{Conclusion}

Academic change is challenging to enact, even when the need for such change is increasingly urgent. Faculty and staff encounter problems that fall outside their normal expertise, requiring the development of new competencies The MACH workshop promotes this skill building, enabling the workshop's participants to lead change. Lessons from these workshops include that preparation and practice are required ahead of the actual attempts to make change. Consultation and partnership are beneficial, recognizing that others bring alternative perspectives and compatible interests. The engineering education adage, "You have to do it to know it," holds true in the change endeavor, as well.

\footnotetext{
References

${ }^{1}$ Engineering Accrediting Board. 1997. Engineering Criteria 2000. Accrediting Board for Engineering and Technology, Baltimore, MD.

${ }^{2}$ Borrego, M., J.E. Froyd, \& T.S. Hall. 2010. Diffusion of engineering education innovations: A survey of awareness and adoption rates in U.S. engineering departments. Journal of Engineering Education 99(3): 185-207.

${ }^{3}$ Daly, A.J. \& K.S. Finnegan. 2010. A bridge between worlds: Understanding network structure to understand change strategy. Journal of Educational Change 11(2): 111-138.

${ }^{4}$ Quinn, R.E. 2010. Deep Change: Discovering the Leader Within. Jossey-Bass, San Francisco, CA.

${ }^{5}$ Henderson, C., A. Beach, \& N. Finkelstein. 2011. Facilitating change in undergraduate STEM instructional practices: An analytic review of the literature. Journal of Research in Science Teaching 48(8): 952-984.
} 
${ }^{6}$ Stone, D., B. Patton, \& S. Heen. 2010. Difficult Conversations. Penguin Books, New York, NY.

${ }^{7}$ Kotter, J.P. \& L.A. Whitehead. Buy-In. Harvard Business Review Press, Boston, MA.

${ }^{8}$ Hohmann, L. 2006. Innovation Games: Creating Breakthrough Products Through Collaborative Play. AddisonWesley, Upper Saddle River, NJ.

${ }^{9}$ Ohno, T. Ask 'Why' five times about every matter. http://www.toyota- global.com/company/toyota traditions/quality/mar_apr_2006.html, accessed 12/17/2013.

${ }^{10}$ SixSigma. Determine the root cause: The five whys. http://www.isixsigma.com/tools-templates/causeeffect/determine-root-cause-5-whys/, accessed 12/17/2013.

${ }^{11}$ United States Environmental Protection Agency. Lean thinking and methods: Kaizen. http://www.epa.gov/lean/environment/methods/kaizen.htm, accessed 12/17/2013.

${ }^{12}$ Covey, S. 2013. The 7 Habits of Highly Effective People: Powerful Lessons in Personal Change. Simon \& Schuster, New York, NY.

${ }^{13}$ Dalrymple, O., D.A. Sears, \& D. Evangelou. 2013. The relative pedagogical value of disassemble/analyze/assemble activities. Advances in Engineering Education 3(4).

${ }^{14}$ Hsiung, C.-m. 2012. The effectiveness of cooperative learning. Journal of Engineering Education 101(1): 119-137.

${ }^{15}$ Prince, M. 2004. Does active learning work? A review of the research. Journal of Engineering Education 93(3): 223-231.

${ }^{16}$ Kapur, M. 2008. Productive failure. Cognition \& Instruction 26(3): 379-424.

${ }^{17}$ Dreyfus, S.E. 2004. The five-stage model of adult skill acquisition. Bulletin of Science \& Technology \& Society 24(3): 177-181.

${ }^{18}$ National Research Council. 2000. How People Learn. National Academy Press, Washington, DC.

${ }^{19}$ Eckel, P.D., M. Green, B. Hill, \& W. Mallon. 1999. On change III. Taking charge of change: A primer for colleges and universities. American Council on Education, Washington, DC.

${ }^{20}$ Tierney, W.G. 1988. Organizational culture in higher education: Defining the essentials. The Journal of Higher Education 59(1): 2-21.

${ }^{21}$ Kezar, A. \& P.D. Eckel. 2002. The effect of institutional culture on change strategies in higher education: universal principles or culturally responsive concepts? The Journal of Higher Education 73(4): 435-460.

${ }^{22}$ Showers, B. \& B. Joyce. 1996. The evolution of peer coaching. Educational Leadership 53(6): 12-17.

${ }^{23}$ Harvard Business Review. 2013. On Teams. Harvard Business Review Press, Boston, MA.

${ }^{24}$ Kezar, A.J. 2001. Understanding and facilitating organizational change in the 21st Century: Recent research and conceptualization. ASHE-ERIC Higher Education Report 28:4. Jossey-Bass, San Francisco, CA.

${ }^{25}$ Eckel, P.D. \& M. Hartley. 2008. Developing academic strategic alliances: Reconciling multiple institutional cultures, policies, and practices. The Journal of Higher Education 79(6): 613-637. 